\title{
COMPARATIVE ANALYSIS OF A FUSION REACTOR BLANKET IN CYLINDRICAL AND TOROIDAL GEOMETRY USING MONTE CARLO
}

BY

D. L. CHAPIN

\section{PLASMA PHYSICS LABORATORY}

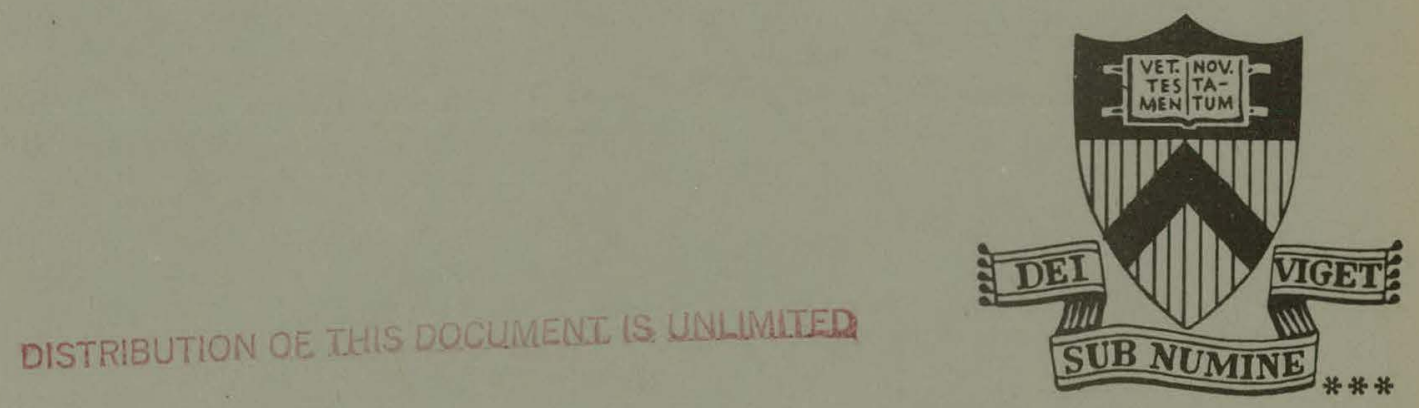

\section{PRINCETON \\ UN IVERSITY PRINCETON, NEW JERSEY}

This work was supported by U. S. Energy Research and Development Administration Contract $\mathrm{E}(11-1)-3073$. Reproduction, translation, publication, use and disposal, in whole or in part, by or for the United States Government is permitted. 


\section{DISCLAIMER}

This report was prepared as an account of work sponsored by an agency of the United States Government. Neither the United States Government nor any agency Thereof, nor any of their employees, makes any warranty, express or implied, or assumes any legal liability or responsibility for the accuracy, completeness, or usefulness of any information, apparatus, product, or process disclosed, or represents that its use would not infringe privately owned rights. Reference herein to any specific commercial product, process, or service by trade name, trademark, manufacturer, or otherwise does not necessarily constitute or imply its endorsement, recommendation, or favoring by the United States Government or any agency thereof. The views and opinions of authors expressed herein do not necessarily state or reflect those of the United States Government or any agency thereof. 


\section{DISCLAIMER}

Portions of this document may be illegible in electronic image products. Images are produced from the best available original document. 


\section{NOTICE}

This report was prepared as an account of work sponsored by the United States Government. Neither the United States nor the United States Energy Research and Development Administration, nor any of their employees, nor any of their contractors, subcontractors, or their employees, makes any warranty, express or implied, or assumes any legal liability or responsibility for the accuracy, completeness or usefulness of any information, apparatus, product or process disclosed, or represents that its use would not infringe privately owned rights.

Printed in the United States of America.

Available from

National Technical Information Service

U. S. Department of Commerce 5285 port Royal Road

Springfield, Virginia 22151

Price: Printed Copy \$ *; Microfiche $\$ 1.45$

NTIS

*Pages

$1-50$

$51-150$

$151-325$

$326-500$

501-1000
Selling Price

$\$ 4.00$

5.45

7.60

10.60

13.60 


\section{Comparative Analysis of a Fusion Reactor}

Blanket in Cylindrical and Toroidal Geometry

Using. Monte Carlo

D. L. Chapin

Plasma Physics Laboratory, Princeton University

Princeton, New.Jersey 08540

ABSTRACT:

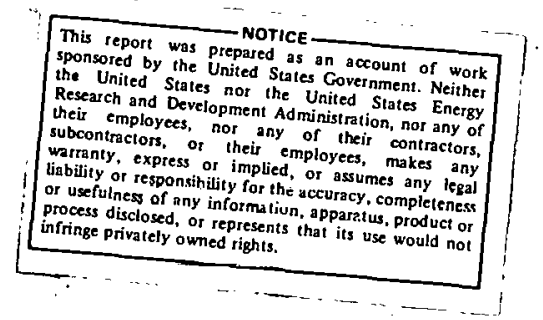

Differences in neutron fluxes and nuclear reaction rates in a non-circular fusion reactor blanket when analyzed in cylindrical and toroidal geometry are studied using Monte Carlo. The investigation consists of three phases - a one-dimensional calculation using a circular approximation to a hexagonal shaped blanket; a two-dimensional calculation of the hexagonal blanket in an infinite cylinder; and a three-dimensional calculation of the blanket in tori of aspect ratios 3 and 5 . The total blanket reaction rate in the two-dimensinnal model is found to be in good agreement with the circular model. The toroidal calculations reveal large variations in reaction rates at different blanket locations as compared to the hexagonal cylinder model, although the total reaction rate is nearly the same for both models. It is shown that the local perturbations in the toroidal blanket are due mainly to volumetric effects, and can be predicted by modifying the results of the infinite cylinder calculation by simple volume factors dependent on the blanket location and the torus major radius. 


\section{Introduction}

Most of the calculations to date of neutron transport in fusion reactor blankets have involved one-dimensional solutions in simple geometry such as cylinders or spheres. In particular, to simulate tokamak reactor blankets the most common method is to approximate the geometry as an infinite circular cylinder and use a discrete ordinates transport code to solve for the neutron flux in the radial direction (for typical examples, see, ref. 1-3). This method is convenient from the standpoint that such codes are readily available, easy to use, and fairly inexpensive to run. However, there may be serious drawbacks to their use in approximating tokamak blankets. The most obvious fault is the use of an infinite cylinder to simulate the toroidal geometry of a tokamak reactor,. hence neglecting the curvature effects of the torus. It is hoped that such effects will cancel each other out so that the one-dimensional approach is valid, although this has not been studied in ... detail. Another .. difficulty is the implicitiy circular cross section required by the one-dimensional cylindrical approach. Recent tokamak fusion reactor designs $(\underline{4}, \underline{5})$ have highly non-circular cross sections that result in asymmetries of the blanket and shield placement about the plasma. The circular approximation to such designs prevents one from studying local variations in nuclear reaction rates in various parts 
of the blanket, such as differences between the inside and outside regions of the torus. Such differences can be very important in the reactor design since an accurate calculation of the flux at the inside of the torus is needed to determine the shielding thickness necessary. to protect the magnets from radiation damage. It will be advantageous to keep this inner shielding to a minimum, so that the reactor power can be maximized (by allowing a higher toroidal magnetic field at the plasma centerline) and the reactor cost can be reduced.

In this paper we investigate perturbations in local neutron fluxes and reaction rates in non-circular cross section blankets both in a cylinder and a torus. The method of calculation used is three-dimensional Monte Carlo, which provides a very flexible method of simulating complex geometries. For this study we chose to use a non-circular blanket in the shape of a hexagon, since this was one of the eisiest shapes to rnnstruct. The analysis proceeded in three phases, assuming for this calculation that we were interested in a one region blanket composed of (homogenized) structure and lithium (to breed tritium). The first step entailed approximating the hexagon shape by a circular cylinder and calculating the neutron flux and tritium breeding rates at different radial zones in the blanket due to a uniformly distributed plasma source of $14 \mathrm{MeV}$ neutrons. The calculations for the circular cylinder were done two different ways - both with a one-dimensional discrete 
ordinates transport code and with the Monte Carlo code - in order to verify that both produced the same results. The second step was to use the Monte. Carlo code to compute fluxes and reaction rates in a hexagonal cross section cylinder. This was really a two-dimensional calculation in which local effects due to the asymmetry of the hexagon.were investigated. The total: reaction rate was compared to the results of the circular cylinder, so that the effect of the non-circularity ... could be determined. The third - step involved a three-dimensional Monté Carlo calculation of hexagonal cross section tori for aspect ratios of both 3 and 5. Fluxes and reaction rates in various parts of the toroidal blanket were compared both for differences between various zones in the torus (e.g. inside vs. outside) for the different aspect ratios and for differences from the hexagonal cylinder. The latter comparison gave an indication of the effect introduced by the toroidal geometry.

In section II the calculational technique used in the study is discussed, inoluding the Munte ciarlo code and associated routines that were. necessary for the analysis. In sectiun III the circular vis. non-circular cylinder results are presented. In section IV the hexagonal cross-section torus is analyzed, and in section $V$ the torus results are compared to those in the cylindrical model. A summary and conclusions drawn from the study are presented in section. VI. 


\section{Method of Calculation}

The Monte Carlo code used in the investigation was the MORSE code(ㅌ) with combinatorial geometry, obtained as CCC-203 from the Radiation Shielding Information Center in Oak Ridge. MORSE has a very flexible geometry package and uses multigroup cross sections for the neutron transport. The ANISN discrete ordinates transport code( 7 ) was used for a comparison to MORSE in the one-dimensional circular cylinder analysis. Exactly the same multigroup cross. section sets were used in both codes, so that any differences in the results due to variations in the nuclear cross sections were eliminated.

In Fig. 1. the hexagonal cross section blanket and a circular model of it are shown. At the center is a plasma of radius $r_{p}$ which is modeled as a uniformly distributed source of $14 \mathrm{MeV}$ neutrons. Surrounding the plasma is a vacuum zone and outside it is the blanket, which is a. homogenized mixture of structural material and lithium for tritium breeding. The dimensions of the circular blanket are determined by the inner radius $r_{1}$ and the outer radius $\mathbf{r}_{2}$; while those of the hexagonal blanket are given by the radius $r_{1}$ to the flat portion of the hexagon and the thickness $t$ of the blanket at that point. It was desired to keep the volumes of the two blankets the same so that the amount of material in each would be equal. For our analysis we chose the inner and outer radii of the circle to be $200 \mathrm{~cm}$ and $300 \mathrm{~cm}$, respectively; and hence the thickness t 
of the hexagon was $92.14 \mathrm{~cm}$. For all cases the plasma radius $r_{p}$ : was chosen as $150 \mathrm{~cm}$. In the toroidal calculations we denote the torus major radius as $R$, and the plasma aspect ratio as $A=R_{t} / r_{p}$.

In order to study asymmetries in. the neutron flux and reaction rates in various parts of the blanket due to the non-circular "cross section, a systematic scheme for specifying regions of interest was needed. The particular method chosen for this analysis is illustrated in figure 1. Assume that we are interested in the flux in a particular part of the blanket, as shown by the cross hatched area. The size and location of the area is specified by four coordinates - the radial position $\mathrm{R}_{\mathrm{z}}$ from the plasma center, the angle $\theta_{z}$ measured from the $x$-axis, the variation $\Delta R$ about $R_{z^{\prime}}$, and the variation $\Delta \theta$ about $\theta_{z^{*}}$ The area of the zune $A_{z}$ 15: $E^{1 \text { tren hy }}$

$$
A_{z}=4 \Delta \theta \quad \Delta R \quad R_{z}
$$

Note that by letting $\Delta \theta=180^{\circ}$, we can determine the average flux in the circular strip from $\left(R_{z}-\Delta R\right)$ to $\left(R_{z}+\Delta R\right)$ around the entire blanket, which is simply the one-dimensional radial case. For the hexagonal blankets, local effects were studied using $\Delta \theta=15^{\circ}, \Delta \mathrm{R}=5 \mathrm{~cm}$, and $\mathrm{R}_{\mathrm{z}}=235,245,255$, $265,275,285 \mathrm{~cm}$. For the hexagonal cross section cylinder, the asymmetry was investigated using $\theta_{z}=0^{\circ}$ and $30^{\circ}$; while 
for the torus we used 7 values of $\theta_{z}$ from $0^{\circ}$ to $180^{\circ}$ in steps of $30^{\circ}$. In both cases the average flux in each radial zone was also calculated by using $\Delta \theta=180^{\circ}$, so that a comparison could be made of the zone averaged rates.

In the Monte Carlo calculations the flux in each zone was computed using a method based on the collision density in that zone. Within a particularizone of volume $V$, the total nuclear reaction. rate that occurs in that volume in the energy group g may be written as

$$
\text { reaction rate in volume } \mathrm{V}=\sum_{\mathrm{T}}^{\mathrm{g}} \phi_{\mathrm{g}} \mathrm{V}
$$

where $\Sigma_{T}^{g}$ is the macroscopic total cross section in group $\mathbf{g}$ for the material in that volume and $\phi_{g}$ is the neutron flux in group $g$. Hence the flux may be calculated by

$$
\phi_{\mathrm{g}}=\left(\text { reaction rate) } /\left(\Sigma_{\mathrm{T}}^{\mathrm{g}} \cdot \mathrm{V}\right)\right.
$$

The reaction rate is the sum of the statistical particle weights used in the Monte Carlo calculation of all particles from a particular energy group that suffer a collision in the given volume. To implement this reaction type flux estimator for MORSE, it was necessary to write a routine that, after each collision, determined in which zone and in what energy group the collision occurred and then stored a contribution to the flux equal to the particle's weight 
divided by $\Sigma_{\mathrm{T}} \mathrm{V}$. This type of estimator is of course not suitable if the number of collisions that occur in a volume is very small, but for the blanket zones used in this study it was found to work quite well.

The blanket used for this analysis was composed of one homogeneous. medium of niobium structure and lithium coolant, with volume fractions of $6 \%$ and $94 \%$, respectively. This composition was chosen since it is.the same as that of the breeding regions in the "benchmark blanket" analyzed by a number of investigators. (ㅇ) To reduce computation time and core storage when running MORSE, a seven group neutron cross section set was formed by collapsing a 52 group set over the benchmark blanket spectrum: This seven group set was found to fairly accurately predict the benchmark blanket breeding reaction rates, and thus was judged suitable for our analysis here. The anisotropic scattertng was represented by a $P_{3}$ Lengendre expansion, and $S_{8}$ quadrature was used in the ANISN run. Since both ANISN and MORSE use the same cross section set, and since in this study we were interested in changes due to different geometries, the exact nature of the cross sections used was relatively unimportant, as long as they were a fairly reasonable representation of the fine group case, which the seven group set was judged to be.

In the analysis of the different geometries there will be two types of results that we will be interested in 
comparing for various zones - integral parameters such as reaction rates, and energy. dependent quantities such as the flux in a particular group $\mathrm{g}$ and zone $\mathrm{k}$, denoted by $\phi_{\mathrm{k}}^{\mathrm{g}}$. The reaction rate in zone $k$ for a reaction type $x$, written as $\mathrm{R}_{\mathbf{k}}^{\mathrm{X}}$, is defined by

$$
\mathrm{R}_{\mathrm{k}}^{\mathrm{x}}=\mathrm{v}_{\mathrm{k}} \sum_{\mathrm{g}=1}^{\mathrm{G}} \phi_{\mathrm{k}}^{\mathrm{g}} \Sigma_{\mathrm{x}}^{\mathrm{g}} \text { reactions/sec }
$$

where $\Sigma_{x}^{g}$ is the macroscopic cross section in group $g$ for a reaction of type $x, v_{k}$ is the volume in zone $k$, and $G$ is the number of energy groups ( 7 here). The two reaction rates of interest are the tritium breeding reactions $\mathrm{Li}^{6}(\mathrm{n}, \alpha) \mathrm{T}$ and $\mathrm{Li}^{7}\left(\mathrm{n}, \mathrm{n}^{\prime} \alpha\right) \mathrm{T}$, for which the suitable reaction cross sections $\Sigma_{\mathrm{X}}^{\mathrm{g}}$ were processed into a seven group format.

III. Circular and Non-Circular Cross Section Cylinders

\section{A. Circular Cylinder}

The first part of the investigation was to calculate the fluxes in a circular cross section infinite cylinder due to a uniformly distributed plasma source of $14 \mathrm{MeV}$ neutrons. The plasma radius was $150 \mathrm{~cm}$ and the inner and outer blanket radii were $200 \mathrm{~cm}$ and $300 \mathrm{~cm}$. Both ANISN and MORSE were used for the calculation so that any differences between the two could be determined hefore the analysis proceeded to 
non-circular shapes, where only MORSE could be used. Fifty-two mesh intervals were used in the ANISN calculation, and then a set of average fluxes and tritium reaction rates were computed for larger zones of thickness $10 \mathrm{~cm}$. The results of the ANISN and. MORSE calculations are given in Table 1 for six zones of interest. Compared in Table 1 are T6 and T7, the tritium production rate per source neutron from the $\mathrm{Li}^{6}$ and $\mathrm{Li}^{7}$ reactions, respectively. AlI results from the Monte Carlo calculation will be quoted as

$$
\mathrm{x} \pm \mathrm{a}, \text { where }
$$

$\mathbf{x}=$ estimated mean value, and

$a=$ standard deviation associated with $x$.

It is seta frum Thh1e 1 that thêre $1 \mathrm{~s}$ very good agreement between the two methods, especially in the T6 values. The T7 values agree well for the inner zones but are within about two standard deviations for the outer zones. Likewise, the total rates in the six zones and in the entire blanket are in closest agreement for $\mathrm{T} 6$, and differ by less than $5 \%$ for T7. These differences might arise from several factors, such as the small number of cross section groups, the Legendre expansion order of the anisotropic scattering, the angular quadrature order, or the number of mesh intervals used in the vacuum zone for the 
ANISN calculation. A comparison of the individual group fluxes showed a similarly good agreement between ANISN and MORSE. Thus the accuracy of MORSE and the flux estimation routine, relative to ANISN, has been established for the infinite circular cylinder case.

\section{B. Hexagonal Cylinder}

In preparation for the full toroidal calculation, a hexagonal cross section cylinder, as shown in Fig. 1, was substituted for the circular cylinder of the previous section. The total areas of these two blankets were kept the same, so that the hexagonal thickness $t$ was $92.14 \mathrm{~cm}$; and the same plasma source was used. Six radial zones were analyzed from $230-290 \mathrm{~cm}$, with $\Delta \mathrm{R}=5 \mathrm{~cm}$. Local variations due to the non-circularity were calculated at zone angles $\theta_{z}$ of $30^{\circ}$ (the hexagon flats) and $0^{\circ}$ (the hexagon corners), w1th $\Delta \theta-15^{\circ}$. By symmetry, the flux was assumed to be the same in all the corner regions $\left(\theta_{z}=0^{\circ}, 60^{\circ}, 120^{\circ}, 180^{\circ}\right)$ and also in all the flat regions $\left(\theta_{z}=30^{\circ}, 90^{\circ}, 150^{\circ}\right)$. An "average" flux for each full circular annulus was calculated by using $\Delta \theta=180^{\circ}$, so that three different profiles of the flux versus $R_{z}$ are available: through the corners; through the flats; and in the annuli.

Tritium production rates corresponding to these fluxes can be computed as reference points for comparison to 
the toroidal cases. In tables 2 and 3 these profiles of T6 and $\mathrm{T} 7$ in the hexagonal. cylinder blanket are given for the annuli, the corners, and the flats, and also for the circular cylinder. Note that for both T6 and T7 the average values fall somewhere within the range of the lower values in the flats and the higher values in the corners. This is due to the fact that the depth of penetration from the surface of the blanket is a function of $\theta_{z}$ as well as $R_{z}$, with substantial differences between the corners and the flats. The fluxes in the annuli represent averages over a range of blanket depths.

It is not of interest to compare the circular cylinder results to the local perturbations introduced by the non-circularity of the hexagon, since clearly a different choice of the circular inner and outer radii would produce ditferent effects. However, since the area of the hexagonal and the circular cross sections are the same, a comparison of the total reaction rates in the entire blanket can be made. As shown in tables 2 and 3 , the T6 rates agree very well while there is about a $6 \%$ difference in the T7 rates. The total tritium production rate (the sum of $\mathrm{T} 6$ and 'I'7) is round to be nearly the same. for both blanket shapes, and hence the non-circularity does not greatly affect the total reaction rate, probably because each blanket is thick enough to capture most of the neutrons. .However, there are significant local effects produced in the hexagon flats and 
corners, which will be compared to corresponding areas in a toroidal blanket in the next sections.

IV. Hexagonal Cross Section Torus

In this section the same hexagonal shaped blanket shown in Fig. 1 is investigated but now as the cross section of a torus. For this study two torus aspect ratios $A$ of 3 and 5 were chosen, with the same plasma source radius of $150 \mathrm{~cm}$. as in the cylindrical case. In Fig. 2 two views from the PICTURE program( $(\underline{9})$ of the torus geometry (for $A=5$ ) used in the MORSE runs are shown.

To investigate the toroidal effects, seven values of the zone angle $\theta_{\mathrm{z}}$ were used, $0^{\circ}$ (outside of torus) to $180^{\circ}$ (inside) in steps of $30^{\circ}$. The width of each sub-zone was again $\Delta \theta=15^{\circ}$, so that an entire annular zone could be covered. Again, six radial zones with $\Delta R=.5 \mathrm{~cm}$. were used for the region from $R_{z}=230 \mathrm{~cm}$ to $290 \mathrm{~cm}$. Symmetry was assumed about the y-axis, and it. was also assumed that the plasma was axisymmetric; thus the flux is only a function of the position in the hexagonal cross section. The boundary condition on the calculation was a pure absorber everywhere outside the blanket, so that any escaping neutrons were simply removed from the system.

In tables 4 and 5 we show the results of the Monte Carlo.calculations for the tritium production rates in 
different.zones of the hexagonal cross section tori. In table 4 the reaction rates $T 6$ from the lithium-6 reaction are shown as a function of radial position in the hexagon flats for $A=3$ and 5 . Note that the flat rates are larger on the outer part of the torus $\left(\theta_{z}=30^{\circ}\right)$ and decrease for areas on the top $\left(90^{\circ}\right)$ and inside $\left(150^{\circ}\right)$. Maximum asymmetry values for $T 6$ in the flats can be found from the ratio of the $30^{\circ}$ and $150^{\circ}$ reaction rates. The $30^{\circ}$ rate is found to be about 1.77 times as great as the $150^{\circ}$ rate for $A=5$, and about $2: 54$ for $A=3$. The effect of different aspect ratios can also be seen by comparing the corrooponding zone rates e.g., the $30^{\circ}$ rate for $A=3$ is about $11 \%$ larger than the $30^{\circ}$ rate for $A=5$, while the $150^{\circ}$ rate is about $23 \%$ smaller for $A=3$. However, we see from tablé 4 that the T6 rates at the top region of the torus $\left(\theta_{z}=90^{\circ}\right)$ are nearly identical for the two aspect ratios, indlcating that perbajs lihe asymmetries in the toroidal blanket reaction rates are due to volume effects since clearly an area on the outer part of the torus corresponds to a larger volume than an area on the inside. These possible volumetrie effeoto nrc investibaled in detail in section $V$.

In table 5 we show the production rates $T 7$ from the lithium-7 reaction as a function of radial position in the hexagon corner areas for $A=3$ and 5 . Note. that again the rates are highest on the outer part of the torus and decrease for more inward points. An interesting ratio is 
the T7 rate on the outside of the torus $\left(\theta_{z}=0^{\circ}\right)$, to that on the inside $\left(\theta_{z}=180^{\circ}\right)$. From table 5 we calculate that the outside rate is 2.06 times as large as the inside rate for $A=5$, while it is 3.05 for $A=3$. By comparing corresponding blanket regions we can also determine the effect of the plasma aspect ratio. For example, the $T 7$ rate on the outside of the torus with $A=3$ is about 14\% larger than the outside rate with $A=5$, while the inside rate is about $23 \%$ less for $A=3$. Hence there $c$ an be significant asymmetry in the reaction rates in different areas of a toroidal blanket with larger rates on the outside of the torus than the inside. This would be a desirable feature from the standpoint of fusion reactor design since the outside blanket modules should be more accessible than those on the inside.

A quantity of interest that can be calculated from the Monte Carlo results is the fraction of the tritium production rate that occurs in a certain portion of the blanket. For example, to find what percent of the T6 or T7 reactions occur in the outer half of the torus blanket in a radial zone from $230-290 \mathrm{~cm}$, we can take the ratio of the sum of the $\theta_{z}=0^{\circ}, 30^{\circ}$, and $60^{\circ}$ values plus one half of the $90^{\circ}$ value to the total value for that area, multiplying by appropriate factors to account for the symmetry in the y-axis. We find that for $A=5$, about $61 \%$ of the $T 6$ reactions and about $62 \%$ of the T7 reactions occur on the outer half of 
the toroidal blanket. Likewise, for $A=3$ we calculate the outer half fractions to be about $65 \%$ for $\mathrm{T} 6$ and $68 \%$ for. $\mathrm{T} 7$. This is a significant amount of asymmetry in the tritium production, since these reactions occur in only $50 \%$.. of the cross sectional area of the blanket.

The fraction $F_{v}$ of the blanket volume that a portion of the cross sectional area occupies can. be calculated by first noting that the volume $v_{z}$ of a zone of the toroidal blanket may be found from

$$
V_{z}=\int_{\theta_{z}-\Delta \theta}^{\theta} \int_{R_{z}-\Delta R}^{R_{z}+\Delta R} 2 \pi\left(R_{t}+r \cos \theta\right) r d r d \theta
$$

where $R_{t}$ is the torus major radius. Thus,

$$
V_{z}=2 \pi A_{z}\left\{R_{t}+R_{z} \cos \theta_{z} \frac{\sin \Delta \theta}{\Delta \theta}\left(1+\frac{1}{3} \frac{\Delta R^{2}}{R_{z}^{2}}\right)\right\},
$$

where equation ( 1 ) has been used for the area $A_{Z} \cdot$ For small $\Delta \theta$ and $\Delta \mathrm{R}$, this reduces to

$$
V_{z}=2 \pi\left(R_{t}+R_{z} \cdot \cos \theta_{z}\right) * A_{z}
$$


Then, using equation (5), we find $F_{V}$ for the outer portion $\left(\theta_{z}=0^{\circ}\right.$ to $60^{\circ}$ plus one-half of $\left.90^{\circ}\right)$ to be

$\left.F_{v}=\frac{1}{R_{t}} \times \frac{1}{12}\left\{6 R_{t}+R_{z}\left[\cos 0^{\circ}+2\left(\cos 30^{\circ}+\cos 60^{\circ}\right)+\cos \cdot 90^{\circ}\right)\right]\right\}$

For the torus used here with $\Lambda=5, F_{v}$ for the outer half of the blanket is about 61\%. Thus there is very close. agreement between the fraction of the $\mathrm{T} 6$ or $\mathrm{T} 7$ in $\mathrm{a}$ particular region of the blanket and the volume fraction of that region compared to the total volume. Similarly good agreement was found in other areas of the blanket - for example the fraction of $\mathrm{T} 6$ or $\mathrm{T} 7$ in the $\theta_{\mathrm{z}}=0^{\circ}$ zone (outside of torus) for $A=3$ was about $14 \%$, while the volume fraction of this zone was: $\simeq 13 \%$ (the area of this zone is about $8 \%$ the blanket cross-section area).

These asymmetries in the nuclear reaction rates in a toroidal blanket and their apparent correspondence to volume factors are analyzed in detail in the next section, where the toroidal and infinite cylinder models are compared.

V. Comparison of Torus and Infinite Cylinder Models

In this section a comparison is made of the results of the Monte Carlo calculation for a hexagonal crose section blanket when the analysis is performed in cylindrical and 
toroidal ( $A=3$ and 5 ) geometry. It is of interest to compare both the radially averaged (annular) reaction rates and fluxes and also the local perturbations at various locations in the toroidal blanket relative to the cylindrical blanket. In table 6. the zone radially averaged $\left(\Delta \theta=180^{\circ}\right)$. tritium production rates $T 6$ and $T 7$ are compared for the cylindrical model and the toroidal model with $A=3$ and 5 . Note that the $\mathrm{T} 6$ rate is nearly the same in the two toroidal blankets but is about $5 \%$ smaller than the T.6 rate predicted in the cylindrical model for zones 1-6. However, the T6 rate in the entire blanket is nearly the same for all three models when the statistical variations are considered. Likewise the $T 7$ reaction rates are nearly identical for both the toroidal .. and cylindrical models, both in the specific zones considered and in the entire blanket. Thus, if one is only interested in gross blanket parameters such as zone averaged reaction rates, these results would tend to show that a calculation with a cylindrical model is suitable for accurately predicting these quantities in a toroidal blanket. However, the results in section IV have shown that significant local variations can occur in a toroidal blanket, and hence it is also of interest to compare these effects with the predictions of the cylindrical model.

To investigate the local effects introduced by the toroidal geometry, we can compare the reaction rates on the outside of the torus $\left(\theta_{z}^{\circ}=0^{\circ}\right)$ and the inside $\left(\theta_{z}=180^{\circ}\right)$ to 
the cylindrical results for the hexagon corners $\left(\theta_{z}=0^{\circ}\right)$. This comparison is shown in table 7 for $A=5$ and table 8 . for $A=3$. For $A=5$, we see that the toroidal outside $T 6$ rate is about. 17\% above the cylindrical value while the inside rate is about $38 \%$ below it. Likewise, for $A=5$ the. T7 outside rate is about $31 \%$ above the cylinder value while the inside rate is about $36 \%$ below. From table 8 for $A=3$, we calculate the T6 asymmetries on the outside and inside to be, respectively, $24 \%$ above and $52 \%$ below. Similarly. for $\mathrm{T} 7$ on the outside and inside, we find differences of about $50 \%$ above and $51 \%$ below the cylindrical value. Note that for each aspect ratio, the $\mathrm{T} 6$ and $\mathrm{T} 7$ inside rates are reduced by about the same magnitude relative to the cylindrical model, but that the asymmetry in the outside rates is about twice as large for T7 as for T6. Since it is clear that there can be large differences between the two calculational models, it is of interest to further study these variations to determine their origin and to see if the cylindrical results can be related to the toroidal results in terms of a correction factor.

The reaction rates compared in tables 7 and 8 . are the total rates per source neutron in the zone volume. Because of this dependence on the zone volume, there is a natural tendency for the rates to be larger on the outer parts of the torus where the volume is larger. This volumetric effect can be eliminated by instead comparing the reaction rate per unit volume, which from equation (2) is given by 


$$
\frac{\text { Reaction Rate }}{\text { Volume }}=\frac{\mathrm{R}_{\mathrm{k}}^{\mathrm{x}}}{\mathrm{V}_{\mathrm{k}}}=\sum_{\mathrm{g}=1}^{\mathrm{G}} \phi_{\mathrm{k}}^{\mathrm{g}} \Sigma_{\mathrm{x}}^{\mathrm{g}} \text { reactions } / \mathrm{cm}^{3} . \mathrm{sec}_{\mathrm{s}}
$$

Then, using equation (5); the rates in the torus may be scaled by a factor of

$$
\frac{R_{t}}{R_{t}+R_{z} \cos \theta_{z}}=\frac{A}{A+\frac{R_{z}}{r_{p}} \cos \theta_{z}}
$$

to produce volumetric rates that may be compared to those calculated in the infinite cylinder model.

In tables 9 and 10 we compare the volumetric reaction rates $\mathrm{T} 6$ and $\mathrm{T} 7$ in the infinite cylinder corner area and in the torus inside and outside regions for the two aspect ratios. These values are calculated by scaling the total volume rates in tables 7 and 8 by the appropriate correction factor as in equation (7). We can see that the volumetric rates are within $10 \%$ of the infinite cylinder results for the T7 rates, in contrast to the results of tables '/ and $y$ where we tound asymmetries in the tori relative to the cylinder of $31 \%$ to $51 \%$. However, the T6 torus volumetric rates do not agree as closely with the cylindrical values, although they are, in general, in better agreement with them than the total volume rates were. For example, for $A=3$ the T6 total volume inside rate is $52 \%$ below the cylinder value 
while the volumetric rate is only about. $10 \%$ above it. Comparing other volumetric T6 rates indicates a range of $10 \%$ to $15 \%$ difference in the tori and the cylinder, of which approximately half can probably. be accounted for from the statistical variation in the Monte Carlo. Similarly improved agreement was found for other volumetric rates in corresponding locations of the cylindrical and toroidal blankets, e.g. in the hexagon flats. Thus these results tend to show that the local variations in reaction rates in a toroidal blanket are mainly due to simple volume effects, with a possible difference of a few percent resulting from the toroidal geometry.

Another consideration in the cylindrical vs. toroidal comparison is the asymmetry in the primary neutron wall load distribution in a torus, since it has been shown(10) that large variations are possible depending on the aspect ratio and wall shape. To investigate these effects, the program used in ref. 10 was modified to handle the hexagonal wall shape of this study with $A=3$ and 5. It was found that for $A=5$, the neutron flux on the outside wall point was about $3 \%$ less than the flux on the inside wall point; while for $A=3$ it was about $6 \%$ smaller. Thus in the toroidal cases there would be an increase in the first group neutron flux at the inside wall area relative to the outside, which would then directly affect the reaction rates. From tables 9 and 10 we can see that, in general, the volumetric tritium production 
rates áre slightly. larger for $\theta_{z}=180^{\circ}$ than for $\theta_{z}=0^{\circ}$. Hence the variations in the neutron first wall loading can provide a further refinement in the comparison of the toroidal and cylindrical blanket analyses. It should be noted that in ref. 10 it was found that the wall. load asymmetry was genërally much greater for a shifted plasma source than for the simple uniform. (constant) source, used here, so that this effect could become more important in relating the cylindrical and toroidal results when different. plasma source distributions are used.

This : comparison of the total blanket tritium. production and of the volumetric reaction rates at various locations in the hexagon blanket indicates that a cylindrical model may be useful in performing the analysis of a toroidal blanket. That is, the effect of the torus geometry on a non-circular blanket seems to be separable into an effect due to the non-circularity plus a simple. geometric effect due to the toroidal curvature. The non-circular effect can be analyzed by an infinite cylinder model of the blanket and then corrections due to the toroidal geometry can be made by scaling the cylindrical results by a simple volume factor to compute nuclear reaction rates in a volume of the blanket (with additional corrections possible to account for wall loading asymmetries). Note that if one is not interested in local variations but instead only in the total rate in the whole 
blanket, then the cylindrical results are in good agreement (for a thick blanket) with those in a torus without needing a correction factor.

It should be noted that this proposed method of analysis is based only on the calculations performed here for a hexagon shaped blanket in an axisymmetric torus with a uniformly distributed plasma source. The particular blanket shape used here (hexagonal) should be relatively unimportant, and in fact was used simply because it was the easiest cross sectional shape to construct in a torus (other than perhaps a square) with the geometry routines available in MORSE. In fact, this method should be applicable to circular blankets, which could be analyzed with a one-dimensional transport code (such as ANISN) and then toroidal geometric factors applied to study local reaction rates.

\section{Summary and Conclusions}

We have investigated variations in neutron fluxes and nuclear reaction rates in non-circular cross section fusion reaotor blankets in both a cylinder and a torus using thre日-dimensional Monte Carlo. The blanket chosen was in the form of a hexagon and was composed of one homogenized medium of structure and lithium. The analysis proceeded in three phases, with the first step being to approximate the hexagon by a circle and perform a one-dimensional discrete 
ordinates calculation along with a Monte Carlo calculation. The actual hexagon shape was then analyzed as the cross section of an . infinite cylinder and then as the cross section of axisymmetric tori of aspect ratios three and five.

The comparison of the circular and hexagonal infinite cylinder models revealed that the total tritium production rate in each blanket was about the șame, although there were significant local variations in different regions of the hexagon due to its non-circularity. The comparison of the hexagon blanket in the cylinder and the torus showed that the total tritium production in the entire blanket was about the same, although there were large variations in the local reaction rates at corresponding regions of the two blankets. However, it was found that these differences were mainly the result of a volumetric effect; that is, the reaction rates per unit volume were in reasonable agreement in the cylindrical and toroidal models. . Hence it appears that tokamak reactor blankets can be effectively studied using an infinite cylinder model, and that corrections due to the toroidal. geometry can be made by scaling the cylindrical. results by a simple volume fiactor to study local variations. If one is uninterested in such local effects, the cylindrical model, seems adequate to predict gross parameters of the blanket such as the tritium breeding rates. 


\section{Acknowledgements}

The author is grateful to Dr. H. Steinberg and Dr. M. Kalos of Mathematical Applications Group, Inc. for their advice on the Monte Carlo calculations.

This work was supported by the U. S. Energy Research and Development Administration Contract E(11-1)-3073. 


\section{References}

1. D. Steiner, "Neutronic Behavior of Two Fusion Reactor Blanket Designs", Nuclear Fusion Reactor Conference Proceedings (British Nuclear Energy Society, London, 1969) p. 483 .

2. W. G. Price, Jr., "Blanket Neutronic Studies for a Fusion Power Reactor", Proceedings of the Fifth Symposium on Engineering Problems of Fusion Research (Institute of, Electric and Electronics Engineers, New York, 1974), IEEE Pub. No. 73CH0843-3NPS, p. 75.

3. M. A. Abdou, "Nuclear Design of Blanket and Shield for a Tokamak Experimental Power Reactor", Trans. "Am. Nuc1. Soc. 21,27 (1975).

4. "A Fusion Power Plant", R. G. Mills, ed., Princeton Plasma Physics Laboratory Report MATT-1050 (1974).

5. B. Badger, et. al., "Wisconsin Toroidal Fusion Reactor Design", University of W1scunsin keport UWFDM-68 (1974).

6. M. B. Emmett, "The MORSE Monte Carlo Radiation Transport Code System", , Oak Ridge National Laboratory Report ORINL-4972 (1975). 
7. W. W. Engle, Jr., "A User's Manual for ANISN", Oak Ridge Gaseous Diffusion Plant Report K-1693 (1967).

8. D. Steiner, "Analyses of a Bench-Mark Calculation of Tritium Breeding in a. Fusion Reactor Blanket", Oak Ridge National .Laboratory Report. ORNL-TM-4177 (1973).

9. E. A. Straker, W. H. Scott, Jr., and N..R. Byrn, "The Morse Code with Combinatorial Geometry", Science Applications Incorporated, La Jolla, California, Report No. SAI-72-511-LJ, May, 1972.

10. D. L. Chapin and W. G. Price, Jr., "A Comparison of the D-T Neutron Wall Load Distributions in Several Tokamak Fusion Reactor Designs", Princeton Plasma Physics Laboratory Report MATT-1186 (1975). 


\begin{tabular}{|c|c|c|c|c|c|c|}
\hline $\begin{array}{l}\text { Zone } \\
\text { Number }\end{array}$ & $\begin{array}{l}\text { Zone } \\
\text { Radii }(\mathrm{cm})\end{array}$ & $\begin{array}{l}\text { T6, read } \\
\text { neutron } \\
\text { ANISN }\end{array}$ & $\begin{array}{l}\text { ions per } \\
\text { rom } \mathrm{Li}^{6}\end{array}$ & source & $\begin{array}{l}\text { T7, react } \\
\text { neutron } \mathrm{f} \\
\text { ANISN }\end{array}$ & $\begin{array}{l}\text { ns per source } \\
\text { MORSE }\end{array}$ \\
\hline 1 & $230-240$ & .10603 & .10488 & \pm .00149 & .059081 & $.059909 \pm .001434$ \\
\hline 2 & $240-250$ & .087218 & .083785 & \pm .001198 & .036885 & $.038207 \pm .002029$ \\
\hline 3 & $250-260$ & .069766 & .068753 & \pm .000941 & .022941 & $.023850 \pm .000699$ \\
\hline 4 & $260-270$ & .054142 & .053345 & \pm .000977 & .014200 & $.014918 \pm .000561$ \\
\hline 5 & $270-280$ & .040322 & $.03975 \overline{8}$ & \pm .000624 & .0087308 & $.0098390 \pm .0000404$ \\
\hline G & $380-290$ & . ก27956 & .027520 & \pm .000682 & .0052962 & $.0062202 \pm .0004104$ \\
\hline Total, & s $1-6$ & .38543 & .37804 & \pm .00252 & .14713 & $.15294 \pm .00275$ \\
\hline \multicolumn{2}{|c|}{ Total; Whole Blanket } & .81890 & .82443 & \pm .01125 & .65407 & $.62568 \pm .00476$ \\
\hline
\end{tabular}

764172

Table 1. Comparison of tritium production rates as calculated by ANISN and MORSE for a une-dimensional oiroular oylindor. 


\begin{tabular}{|c|c|c|c|c|c|}
\hline \multirow{2}{*}{$\begin{array}{l}\text { Zone } \\
\text { Number }\end{array}$} & \multirow{2}{*}{$\begin{array}{l}\begin{array}{l}\text { Jone } \\
\text { Radi } i(\mathrm{~cm})\end{array} \\
230-240\end{array}$} & $\begin{array}{c}\text { Circular } \\
\text { Cylinder T6, } \\
\text { HORSE }\end{array}$ & AVERAGE & onal Cylinder T6. fr & $\operatorname{FLATS}\left(\theta_{z}=30^{\circ}\right)$ \\
\hline & & $.10488 \pm .00149$ & $.12518 \pm .00200$ & $.13544 \pm .00344$ & $.11496 \pm .00168$ \\
\hline 2 & $240-250$ & $.083785 \pm .001198$ & $.10659 \pm .00127$ & $.11771 \pm .00209$ & $.095509 \pm .001530$ \\
\hline 3 & $250-260$ & $.068753 \pm .000941$ & $.085024 \pm .001630$ & $.095492 \pm .002347$ & $.074564 \pm .002073$ \\
\hline 4 & $260-270$ & $.053345 \pm .000977$ & $.067898 \pm .001162$ & $.078518 \pm .002053$ & $.057281 \pm .000975$ \\
\hline 5 & $270-280$ & $.039758 \pm .000624$ & $.052394 \pm .000926$ & $.062121+.001601$ & $.042670 \pm .001111$ \\
\hline 6 & & $.027520 \pm .000682$ & $.038165 \pm .000582$ & $.046794 \pm .000960$ & $.029541 \pm .000963$ \\
\hline \multicolumn{2}{|c|}{ Total Whole } & $.82443 \pm .01125$ & $.81524 \pm .01932$ & & \\
\hline
\end{tabular}

\section{8}

Table 2. Tritium production rates (reactions per source neutron) from Lithium-6 in the circular and hexagonal cross section. cylinders.

\begin{tabular}{|c|c|c|c|c|c|}
\hline \multirow{2}{*}{$\begin{array}{l}\text { Zone } \\
\text { Number }\end{array}$} & \multirow{2}{*}{$\begin{array}{l}\text { Zone } \\
\text { Radii } \\
\text { (cm) }\end{array}$} & \multirow{2}{*}{$\begin{array}{l}\text { Circular } \\
\text { Cylinder T7 } \\
\text { HORSE }\end{array}$} & \multicolumn{3}{|c|}{ Hexagonal Cylinder T7 from MORSE } \\
\hline & & & AVERAGE & CORNERS $\left(\theta_{z}=0^{\circ}\right)$ & $\operatorname{FLATS}\left(\theta_{z}=30^{\circ}\right)$ \\
\hline 1 & $230-240$ & $.059909 \pm .001434$ & $.10703 \pm .00138$ & $.14372 \pm .00329$ & $.070346 \pm .002113$ \\
\hline 2 & $240-250$ & $.038207 \pm .002029$ & $.068098 \pm .001264$ & $.091630 \pm .002241$ & $.044564 \pm .002299$ \\
\hline 3 & $250-260$ & $.023850 \pm .000699$ & $.041508 \pm .001042$ & $.056616 \pm .001744$ & $.026401 \pm .001305$ \\
\hline 4 & $260-270$ & $.014918 \pm .000561$ & $.025829 \pm .001175$ & $.035361 \pm .001793$ & $.016298 \pm .001176$ \\
\hline 5 & $270-280$ & $.0098390 \pm .0006464$ & $.016520 \pm .000651$ & $.022829 \pm .001277$ & $.010212 \pm .000773$ \\
\hline 6 & $280-290$ & $.0062202 \pm .0004104$ & $.010905 \pm .000637$ & $.015940 \pm .001312$ & $.0058700 \pm .0006974$ \\
\hline \multicolumn{2}{|c|}{$\begin{array}{c}\text { Total, Whole } \\
\text { Blanket }\end{array}$} & $.62568 \pm .00476$ & $.66376 \pm .01181$ & & \\
\hline
\end{tabular}

Table 3. Tritium production rates (reactions for source neutron) from LIthium-7 in the circular and hexagonal cross section cylinders. 


$$
-30-
$$

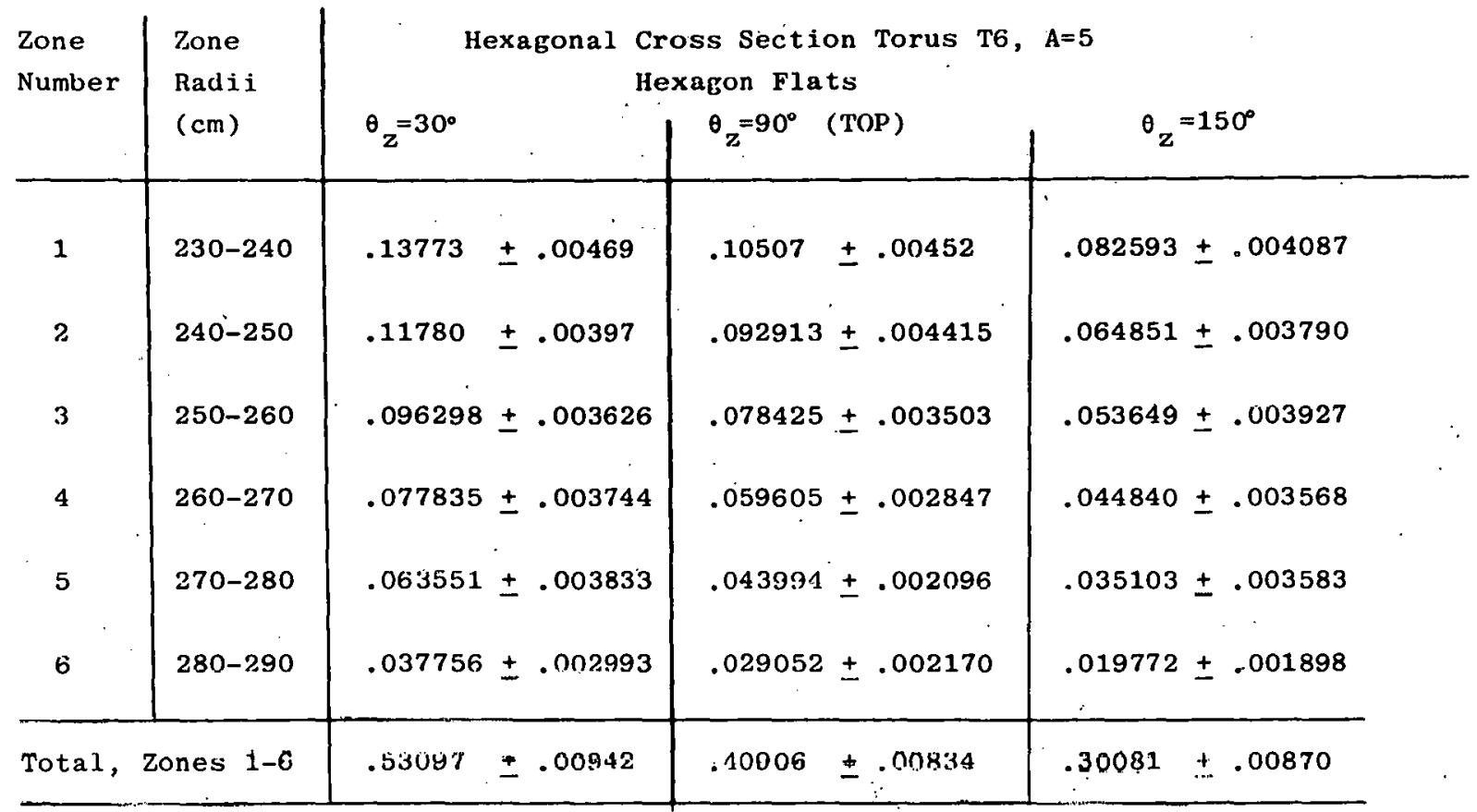

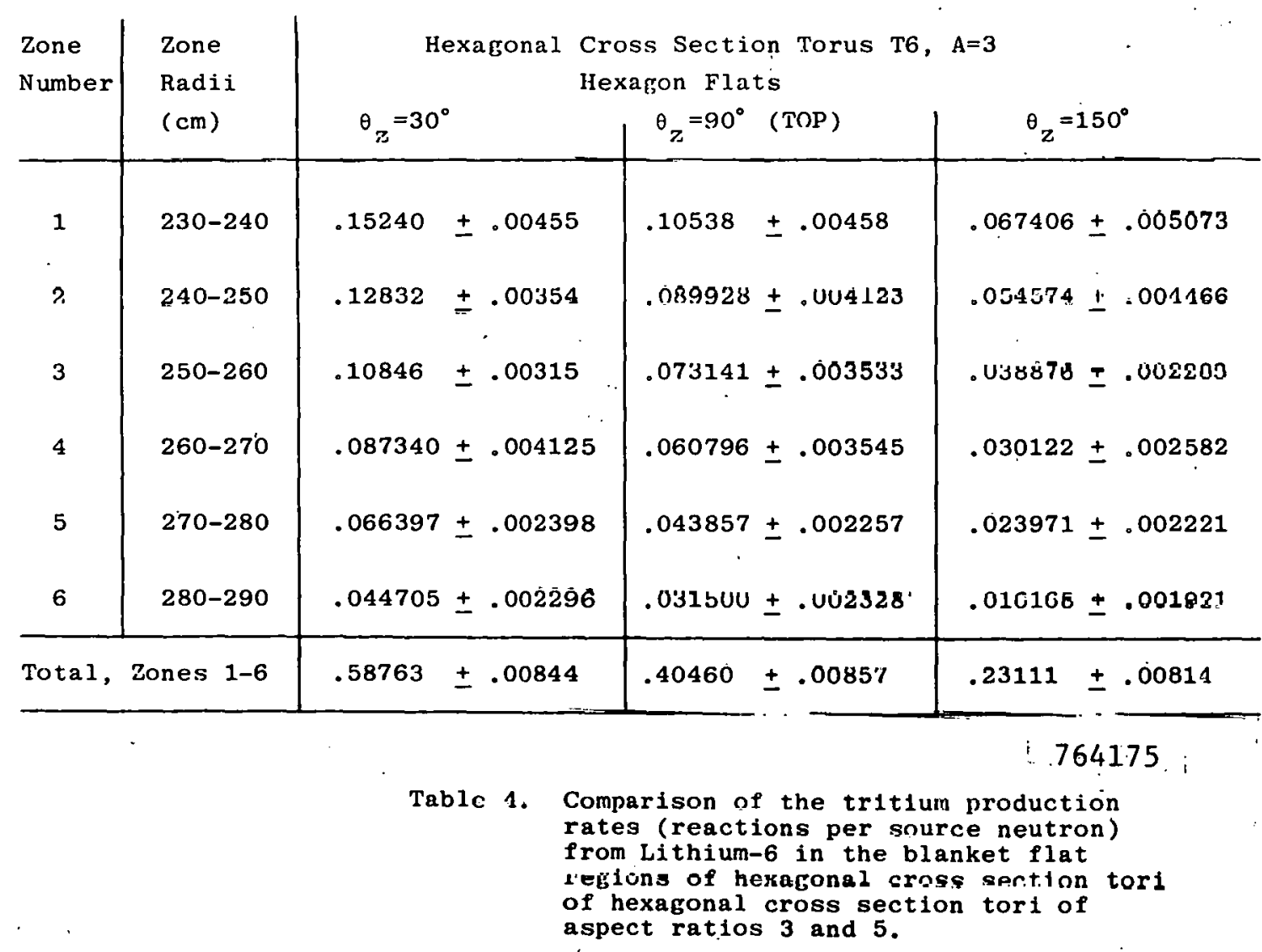




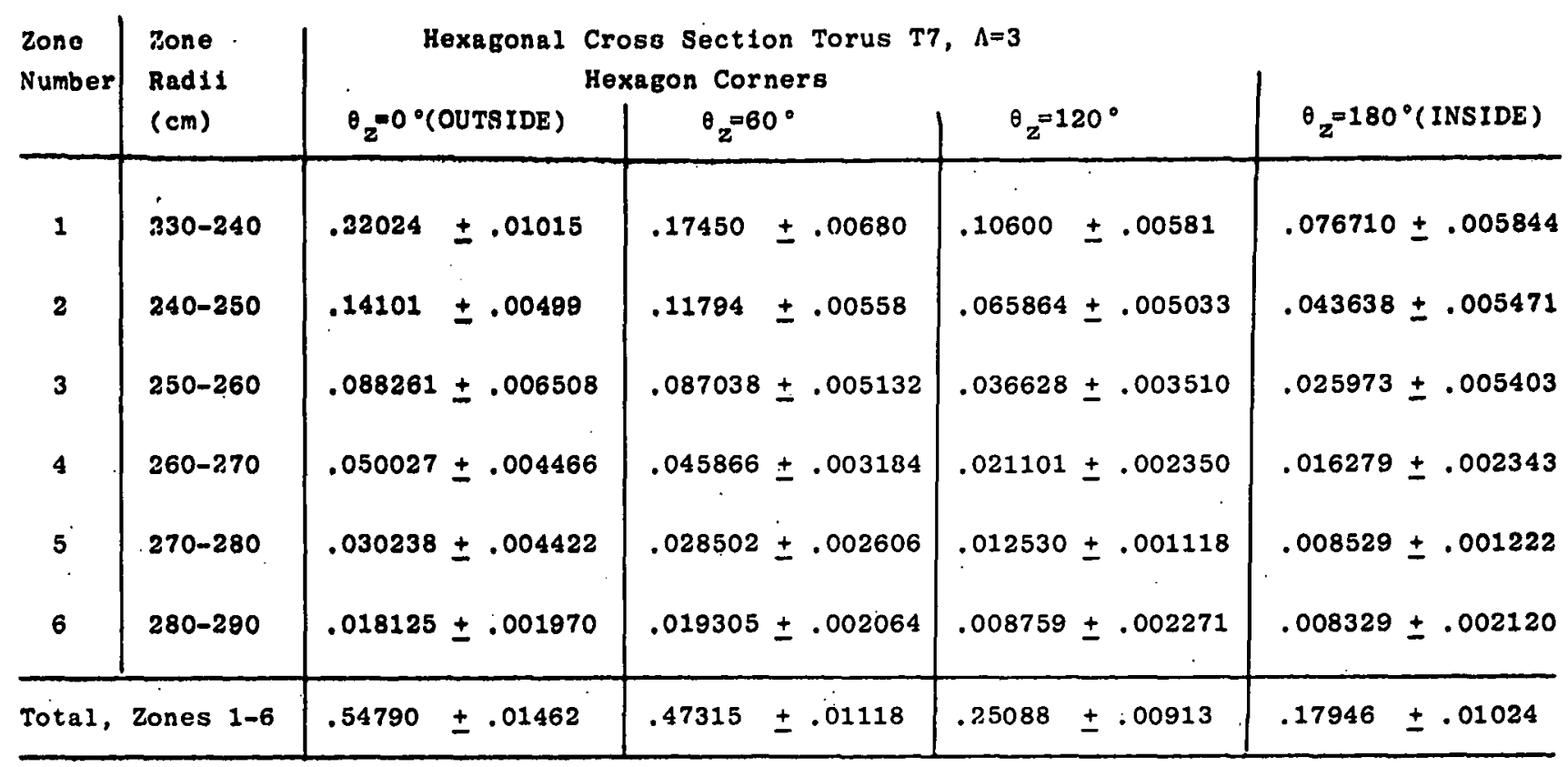

\begin{tabular}{|c|c|c|c|c|c|}
\hline \multirow[t]{2}{*}{$\begin{array}{l}\text { Zone } \\
\text { Number }\end{array}$} & \multirow{2}{*}{$\begin{array}{l}\text { Zone } \\
\text { Radii } \\
(\mathrm{cm})\end{array}$} & \multicolumn{3}{|c|}{$\begin{array}{c}\text { Hexagonal Cross Section Torus T7, } \Lambda=5 \\
\text { Hexagon Corners }\end{array}$} & \multirow[b]{2}{*}{$\theta_{z}=180^{\circ}($ INSIDE $)$} \\
\hline & & $\theta_{z}=0^{\circ}$ (OUTSIDE) & $\theta_{z}=60^{\circ}$ & $\theta_{z}=120^{\circ}$ & \\
\hline 1 & $230<240$ & $.20683 \pm .01041$ & $.17715 \pm .00733$ & $.10899 \pm .00607$ & $.095361 \pm .010296$ \\
\hline 2 & $240-250$ & $.11550 \pm .01016$ & $.10082 \pm .00513$ & $.07034 \pm .004610$ & $.059519 \pm .006154$ \\
\hline 3 & $250-260$ & $.070820 \pm .007307$ & $.064722 \pm .003763$ & $.042810 \pm .003042$ & $.038034 \pm .004235$ \\
\hline 4 & $260-270$ & $.037439 \pm .003941$ & $.037047 \pm .003391$ & $.027140 \pm .002972$ & $.019921 \pm .002657$ \\
\hline 5 & $270-280$ & $.031372 \pm .003589$ & $.028494 \pm .002901$ & $.015196 \pm .002600$ & $.013898 \pm .001886$ \\
\hline 6 & $280-290$ & $.018932 \pm .002837$ & $.018880 \pm .001650$ & $.010682 \pm .001570$ & $.0063046 \pm .0011667$ \\
\hline otal, & ones $1-6$ & $.48120 \pm .01736$ & $.42731 \pm .01088$ & $.27519 \pm .00924$ & $.23304 \pm .01318$ \\
\hline
\end{tabular}

\section{9}

Table 5. Comparison of the tritium production rates (reactions per source neutron) from Lithium-7 in the blanket corner regions of hexagonal cross section tor 1 of aspect ratios 3 and 5 . 


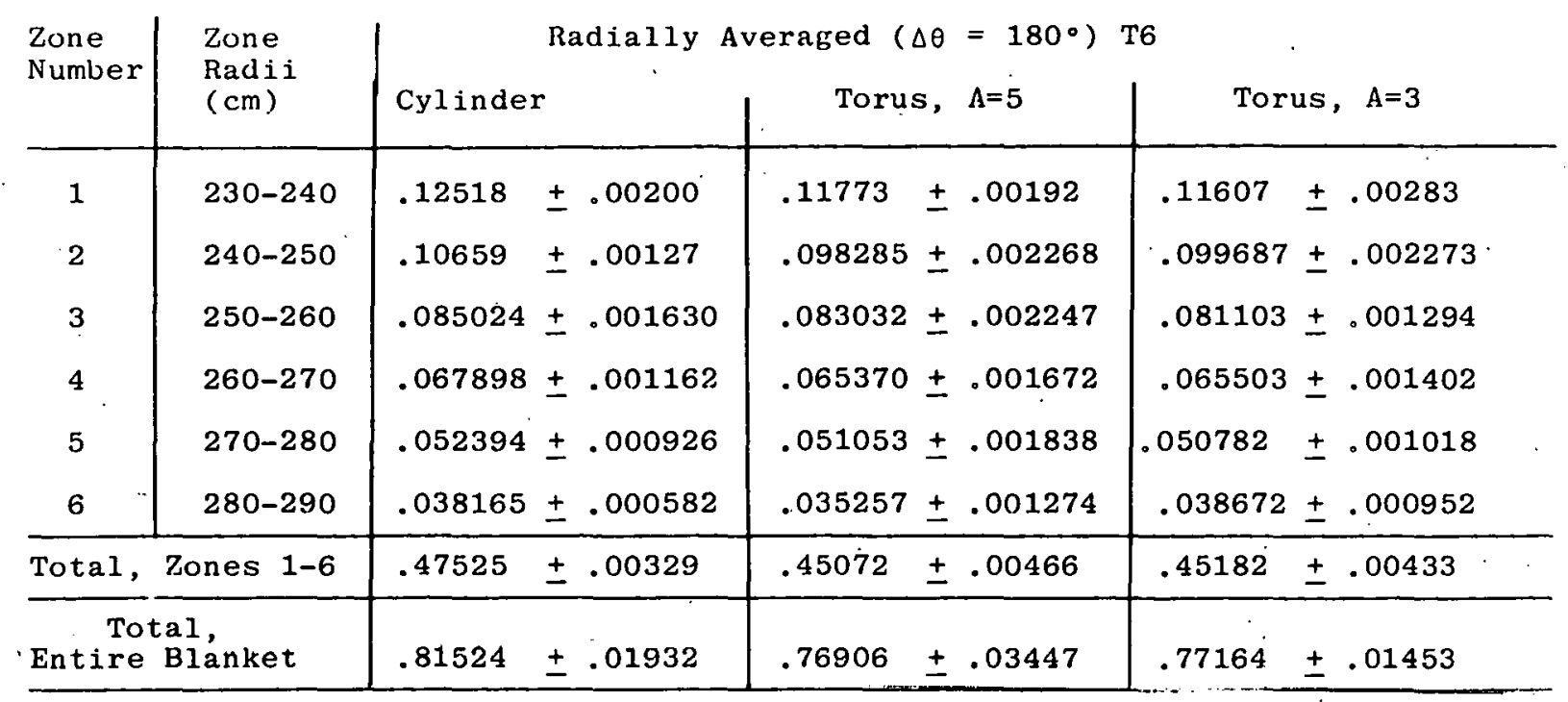

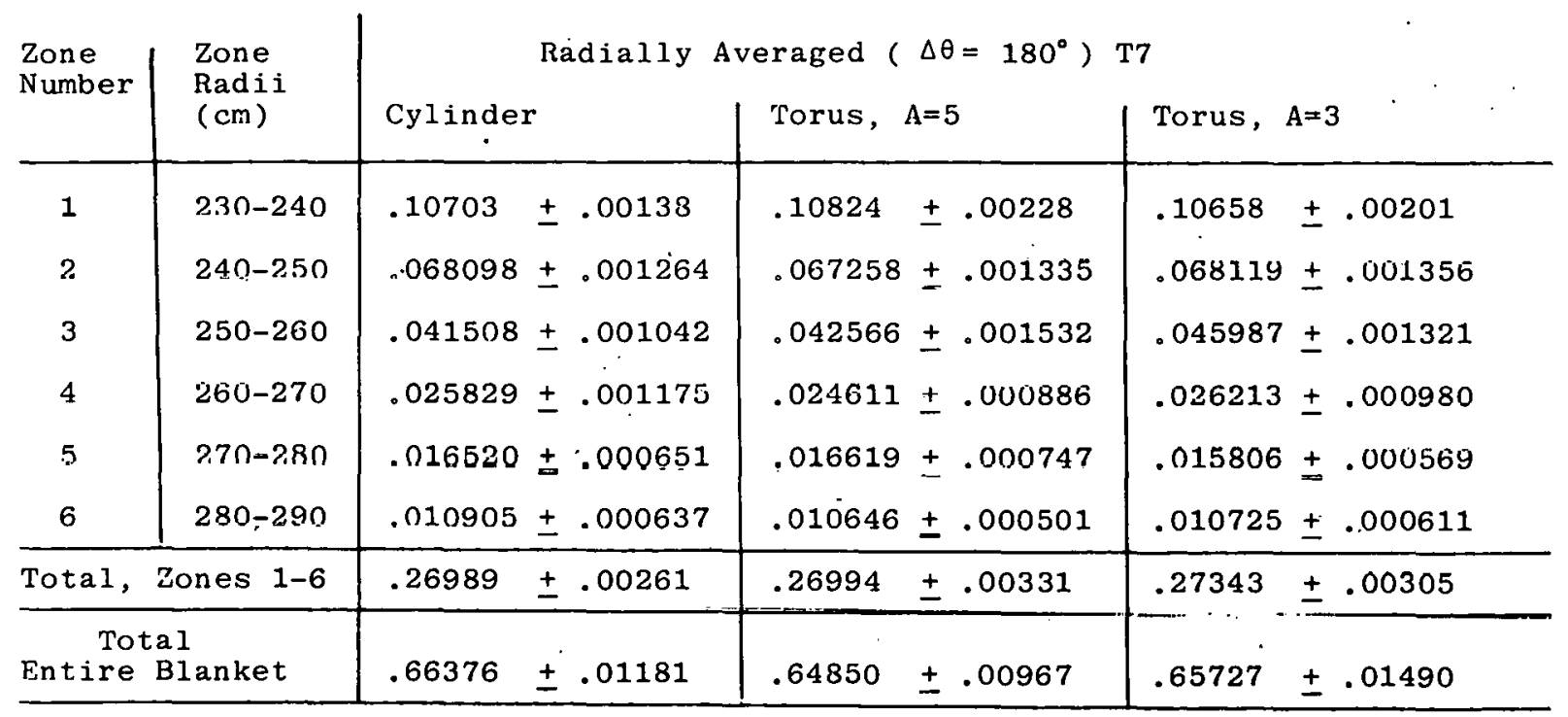

76417.6

Table 6. Comparison of the radially averaged $\left(\Delta \theta=180^{\circ}\right)$ tritium production rates (reactions per source neutron) from Lithium-6 and Lithium-7 in the annuli and the entire blanket of the hexagonal cross section cylinder and the hexagonal cross section tori of aspect ratios 3 and 5 . 


\begin{tabular}{c|c|c|c|c|c}
$\begin{array}{l}\text { Zone } \\
\text { Number }\end{array}$ & $\begin{array}{l}\text { Zone } \\
\text { Radii } \\
(\mathrm{cm})\end{array}$ & \multicolumn{4}{|c}{ Cylinder and Torus T6, Hexagon Corners } \\
& & Cylinder $\left(\theta_{z}=0^{\circ}\right)$ & Torus $\left(\theta_{z}=0^{\circ}\right)$ & $\begin{array}{c}\text { Torus } A=5 \\
\text { Torus }\left(\theta_{z}=180^{\circ}\right)\end{array}$ \\
\hline 1 & $230-240$ & $.13544 \pm .00344$ & $.16116 \pm .00473$ & $.088504 \pm .004908$ \\
2 & $240-250$ & $.11771 \pm .00209$ & $.13400 \pm .00468$ & $.078884 \pm .005053$ \\
3 & $250-260$ & $.095492 \pm .002347$ & $.11560 \pm .00430$ & $.057247 \pm .005115$ \\
4 & $260-270$ & $.078518 \pm .002053$ & $.087606 \pm .003014$ & $.050713 \pm .004712$ \\
5 & $270-280$ & $.062121 \pm .001601$ & $.072010 \pm .003508$ & $.031545 \pm .002817$ \\
6 & $280-290$ & $.046794 \pm .000960$ & $.056523 \pm .003725$ & $.027453 \pm .002676$ \\
\hline
\end{tabular}

\begin{tabular}{|c|c|c|c|c|}
\hline $\begin{array}{l}\text { Zone } \\
\text { Number }\end{array}$ & $\begin{array}{l}\text { Zone } \\
\text { Radii } \\
(\mathrm{cm})\end{array}$ & $\begin{array}{r}\text { Cylinder } \\
\text { Cylinder }\left(\theta_{z}=0^{\circ}\right)\end{array}$ & $\begin{array}{l}\text { Torus T7, Hexagon } \\
\text { Torus }\left(\theta_{z}=0^{\circ}\right)\end{array}$ & $\begin{array}{l}\text { orners } \\
\text { A }=5 \\
\text { Torus }\left(\theta_{z}=180^{\circ}\right)\end{array}$ \\
\hline 1 & $230-240$ & $.14372 \pm .00329$ & $.20683 \pm .01041$ & $.095361 \pm .010296$ \\
\hline 2 & $240-250$ & $.091630 \pm .002241$ & $.11580 \pm .01016$ & $.059519 \pm .006154$ \\
\hline 3 & $250-260$ & $.056615 \pm .001744$ & $.070820 \pm .007307$ & $.038034 \pm .004235$ \\
\hline 4 & $260-270$ & $.035361 \pm .001793$ & $.037439 \pm .003941$ & $.019921 \pm .002657$ \\
\hline 5 & $270-280^{\circ}$ & $.022829 \pm .001277$ & $.031372 \pm .003589$ & $.013898 \pm .001886$ \\
\hline 6 & $280-290$ & $.015940 \pm .001312$ & $.018932 \pm .002837$ & $.0063064 \pm .0011667$ \\
\hline \multicolumn{2}{|c|}{ Total, Zones 1-6 } & $.36610 \pm .00505$ & $.48120 \pm .01736$ & \pm .01318 \\
\hline
\end{tabular}

764174

Table 7. Comparison of the tritium production rates (reactions per source neutron) from Lithium-6 and Lithium-7 in the blanket corner regions of the hexagonal cross section cylindor and hexagonal cross section torus of aspect ratio 5 . 


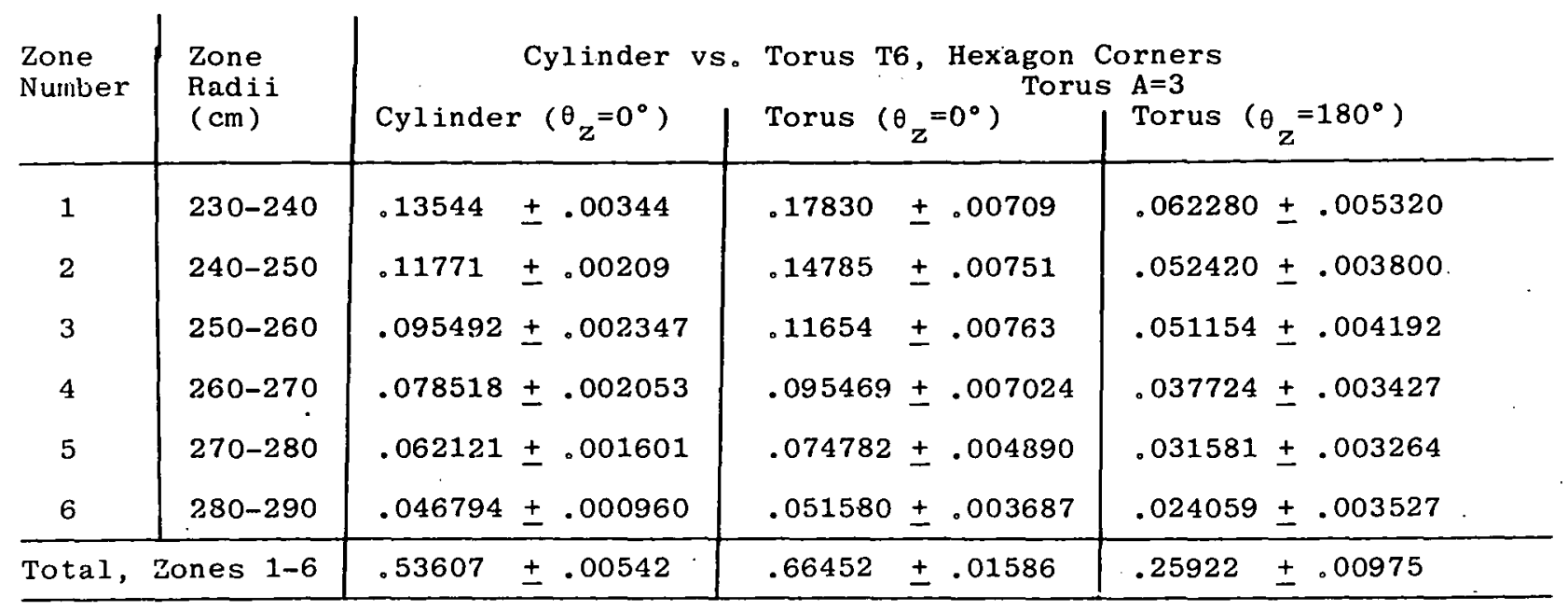

\begin{tabular}{|c|c|c|c|c|}
\hline $\begin{array}{l}\text { Zone } \\
\text { Number }\end{array}$ & $\begin{array}{l}\text { Zone } \\
\text { Radii } \\
(\mathrm{cm})\end{array}$ & $\begin{array}{r}\text { Cylinder } \\
\text { Cylinder }\left(\theta_{z}=\infty^{\circ}\right)\end{array}$ & $\begin{array}{l}\text { Torus } \mathrm{T} 7 \text {, Hexagon } \\
\text { Torus }\left(\theta_{z}=0^{\circ}\right) \text { Toru }\end{array}$ & $\begin{array}{l}\text { Orners } \\
\begin{array}{l}A=3 \\
\text { Torus }\left(\theta_{z}=180^{\circ}\right)\end{array}\end{array}$ \\
\hline 1 & $230-240$ & $.14372 \pm .00329$ & $.22024 \pm .01015$ & $.076710 \pm .005844$ \\
\hline 2 & $240-250$ & $.091630 \pm .002241$ & $.14101 \pm .00499$ & $.043638 \pm .005471$ \\
\hline 3 & $250-260$ & $.056615 \pm .001744$ & $.088261 \pm .006$ bu8 & $: 0259731.005103$ \\
\hline 4 & $260-270$ & $.035361 \pm .001793$ & $.050027 \pm .004466$ & $.016279 \pm .002343$ \\
\hline 5 & $270-280$ & $.022829 \pm .001277$ & $.030238 \pm .004422$ & $.008527 \pm .001222$ \\
\hline 6 & $280-290$ & $.015940 \pm .001312$ & $.018125 \pm .001970$ & $.008329 \pm .002120$ \\
\hline \multicolumn{2}{|c|}{ Total, Zones 1-6 } & $.36610 \pm .00505$ & $.54790 \pm .01462$ & $.17946 \pm .01023$ \\
\hline
\end{tabular}

764173

Table 8. Comparison of the tritium production rates (reactions per source neutron) from Lithium-6 and Lithium-l in the blanket corner regions of the hexagonal cross section cylinder and hexagonal cross section torus of aspect ratio 3 . 


\begin{tabular}{|c|c|c|c|c|c|}
\hline \multirow{2}{*}{$\begin{array}{l}\text { Zone } \\
\text { Number } \\
1\end{array}$} & \multirow{2}{*}{$\begin{array}{l}\text { Zone } \\
\text { Radii } \\
(\mathrm{cm})\end{array}$} & \multicolumn{3}{|c|}{$\begin{array}{l}\left.\text { Cylinder and Torus Volumetric T6 Reaction Rate (per } \mathrm{cm}^{3}\right) \\
\text { Torus Values Scaled by Volume Correction Factor } \\
\text { Cylinder }\left(\theta_{z}=0^{\circ}\right) \quad \mid \text { Torus }\left(\theta_{z}=0^{\circ}\right) \text { Torus } A=5 \\
\text { Torus }\left(\theta_{z}=180^{\circ}\right)\end{array}$} & \\
\hline & & $.13544 \pm .00344$ & $.12271 \pm .00360$ & $.12889 \pm .00715$ & \\
\hline 2 & $240-250$ & $.11771 \pm .00209$ & $.10101 \pm .00353$ & $.11715 \pm .00750$ & \\
\hline 3 & $250-260$ & $.095492 \pm .002347$ & $.086269 \pm .003209$ & $.086737 \pm .00775$ & \\
\hline 4 & $260-270$ & $.078518 \pm .002053$ & $.064733 \pm .002227$ & $.078422 \pm .007287$ & \\
\hline 5 & $270-280$ & $.062121 \pm .001601$ & $.052690 \pm .002567$ & $.049807 \pm .004448$ & \\
\hline 6 & $280-290$ & $.046794 \pm .000960$ & $.040959 \pm .002699$ & $.044280 \pm .004317$ & \\
\hline$a 1$, & s $1-6$ & $.53607 \pm .00542$ & $.46636 \pm .00737$ & $.50985 \pm .01622$ & \\
\hline
\end{tabular}

\begin{tabular}{|c|c|c|c|c|}
\hline \multirow{3}{*}{$\begin{array}{l}\begin{array}{l}\text { Zone } \\
\text { Number }\end{array} \\
1\end{array}$} & \multirow{3}{*}{$\begin{array}{l}\begin{array}{l}\text { Zone } \\
\text { Radii } \\
(\mathrm{cm})\end{array} \\
230-240\end{array}$} & \multicolumn{3}{|c|}{$\begin{array}{l}\text { Cylinder and Torus Volumetric T7 Reaction Rate (per } \mathrm{cm}^{3} \text { ) } \\
\text { Torus values Scaled by Volume Correction Factor } \\
\text { Torus } A=5\end{array}$} \\
\hline & & Cylinder $\left(\theta_{z}=0^{\circ}\right)$ & Torus $\left(\theta_{z}=0^{\circ}\right)$ Torus & Torus $\left(\theta_{z}=180^{\circ}\right)$ \\
\hline & & $.14372 \pm .00329$ & $.15748 \pm .00793$ & $.13888 \pm .01499$ \\
\hline 2 & $240-250$ & $.091630 \pm .002241$ & $.087288 \pm .007656$ & $.088395 \pm .009140$ \\
\hline 3 & $250-260$ & $.056615 \pm .001744$ & $.052851 \pm .005453$ & $.057627 \pm .006417$ \\
\hline 4 & $260-270$ & $.035361 \pm .001793$ & $.027664 \pm .002912$ & $.030806 \pm .004109$ \\
\hline 5 & $270-280$ & $.022829 \pm .001277$ & $.022955 \pm .002626$ & $.021944 \pm .002978$ \\
\hline 6 & $280-290$ & $.015940 \pm .001312$ & $.013719 \pm .002056$ & $.010172 \pm .001882$ \\
\hline tal & es $1-6$ & $.36610 \pm .00505$ & $.35796 \pm .01291$ & $.35536 \pm .02010$ \\
\hline
\end{tabular}

Table 9. Comparison of the volumetric tritium production rates (reactions per $\mathrm{cm}^{3}$ per source neutron - scaled by volumetric correction factors) from Lithium-6 and Lithium-7 in the bianket corner regions of the hexagonal cross section cylinder and hexagonal cross section torus of aspect ratio 5 . 


$$
-36-1
$$

\begin{tabular}{|c|c|c|c|c|}
\hline \multirow{3}{*}{$\begin{array}{l}\begin{array}{l}\text { Zone } \\
\text { Number }\end{array} \\
1\end{array}$} & \multirow{3}{*}{$\begin{array}{l}\begin{array}{l}\text { Zone } \\
\text { Radii } \\
(\mathrm{cm})\end{array} \\
230-240\end{array}$} & \multicolumn{3}{|c|}{$\begin{array}{l}\text { Cylinder and Torus Volumetric T6 Reaction Rate (per } \mathrm{cm}^{3} \text { ) } \\
\text { Torus Values Scaled by Volume Correction Factor } \\
\text { Torus } A=3\end{array}$} \\
\hline & & Cylinder $\left(\theta_{z}=0^{\circ}\right)$ & Torus $\left(\theta_{z}=0^{\circ}\right)$ & Torus $\left(\theta_{z}=180^{\circ}\right)$ \\
\hline & & $.13544 \pm .00344$ & $.11713 \pm .00466$ & $.13036 \pm .01113$ \\
\hline 2 & $240-250$ & $.11771 \pm .00209$ & $.095732 \pm .004864$ & $.11507 \pm .00834$ \\
\hline 3 & $250-260$ & $.095492 \pm .002347$ & $.074385 \pm .004868$ & $.10805 \pm .00967$ \\
\hline 4 & $260-270$ & $.078518 \pm .002053$ & $.060085 \pm .004420$ & $.091762 \pm .008336$ \\
\hline 5 & $270-280$ & $.062121 \pm .001601$ & $.046416 \pm .003035$ & $.081208 \pm .008393$ \\
\hline 6 & $280-290$ & $.046794 \pm .000960$ & $.031580 . \pm .002257$ & $.065614 \pm .009618$ \\
\hline , & 6 & $.53607 \pm .00542$ & $.42226 \pm .01008$ & $.60807 \pm .02288$ \\
\hline
\end{tabular}

\begin{tabular}{|c|c|c|c|c|}
\hline \multirow{2}{*}{$\begin{array}{l}\text { Zone } \\
\text { Number }\end{array}$} & \multirow{2}{*}{$\begin{array}{l}\text { Zone } \\
\text { Radii } \\
(\mathrm{cm})\end{array}$} & \multicolumn{3}{|c|}{$\begin{array}{c}\text { Cylinder and Torus Volumetric T7 Reaction Rate (per } \mathrm{cm}^{3} \text { ) } \\
\text { Torus values Scaled by Volume Correction Factor } \\
\text { Torus } A=3\end{array}$} \\
\hline & & Cylinder $\left(\theta_{z}=0^{\circ}\right)$ & Torus $\left(\theta_{z}=0^{\circ}\right)$ & Torus $\left(\theta_{z}=180^{\circ}\right)$ \\
\hline 1 & $230-240$ & $.14372 \pm .00329$ & $.14468 \pm .00667$ & $.16056 \pm .01223$ \\
\hline 2 & $240-250$ & $.091630 \pm .002241$ & $.091302 \pm .003231$ & $.095780 \pm .012009$ \\
\hline 3 & $250-260$ & $.056615 \pm .001744$ & $.056337 \pm .004154$ & $.059938 \pm .012168$ \\
\hline 4 & $280-270$ & $.035361+.001783$ & $.031486 \pm 002810$ & $.039597 \pm .005699$ \\
\hline 5 & $270-280$ & $.022829 \pm .001277$ & $.018788 \pm .002746$ & $.031032 \pm .003143$ \\
\hline 6 & $280-290$ & $.015940 \pm .001312$ & $.011097 \pm .001206$ & $.017715 \pm .004500$ \\
\hline \multicolumn{2}{|c|}{ Total, Zones 1-6 } & $.36610 \pm .00505$ & $.34816 \pm .00929$ & $.42098 \pm .02401$ \\
\hline
\end{tabular}

Table 10. Comparison of the volumetric tritlum production rates (reactions per $\mathrm{cm}^{3}$ per source neutron - scaled by volumetric correction factors) from Lithium 8 and Lithium-7 in the blanket corner regions of the hexagonal cross section cylinder and hexagonal cross section torus of aspect ratio 3 . 


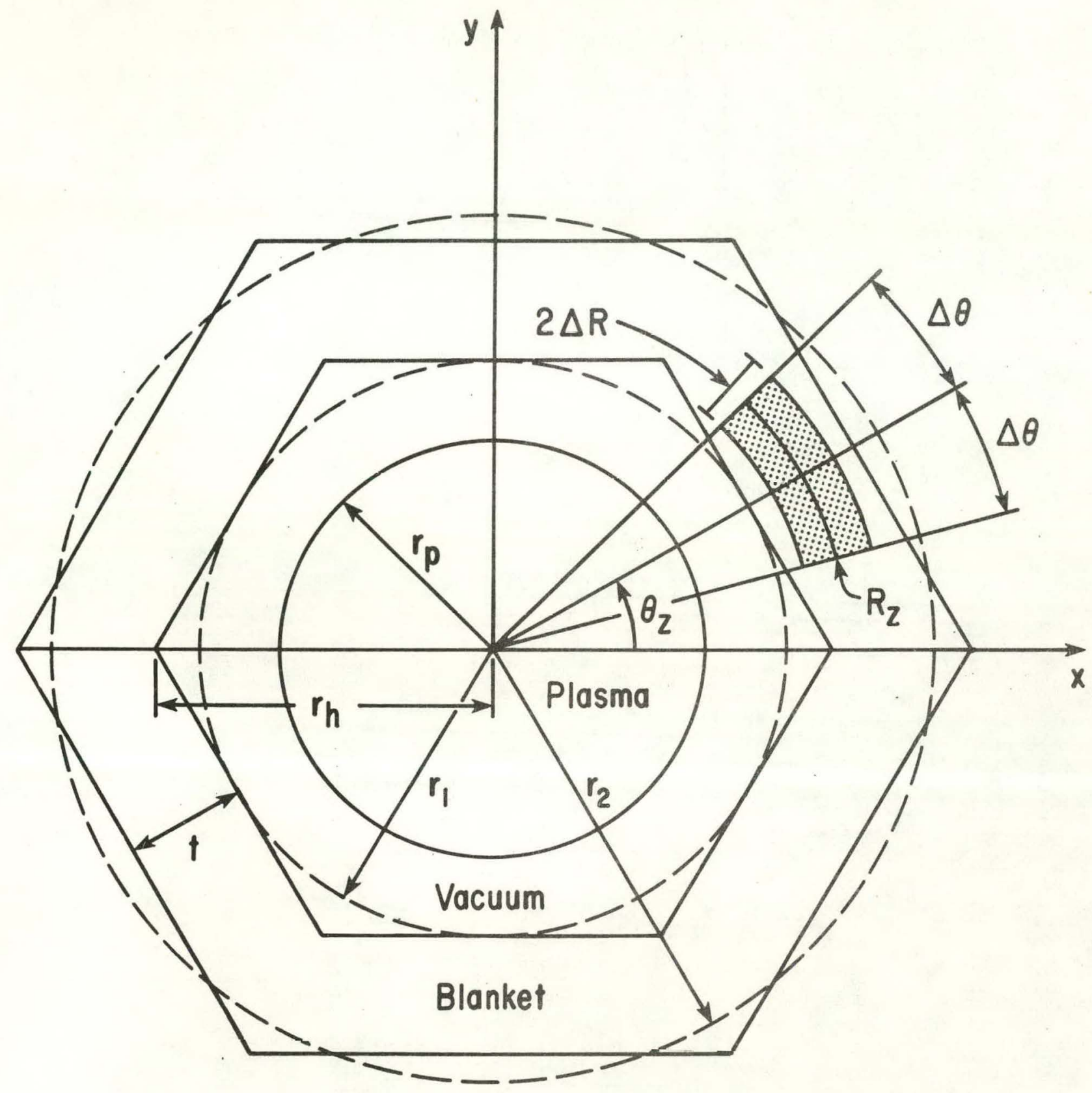

Hexagonal Cross Section Blanket Geometry

Fig. 1. Hexagonal 764167 approximation toxanal cross section blanket and a circular zones of interest for the calculation. 


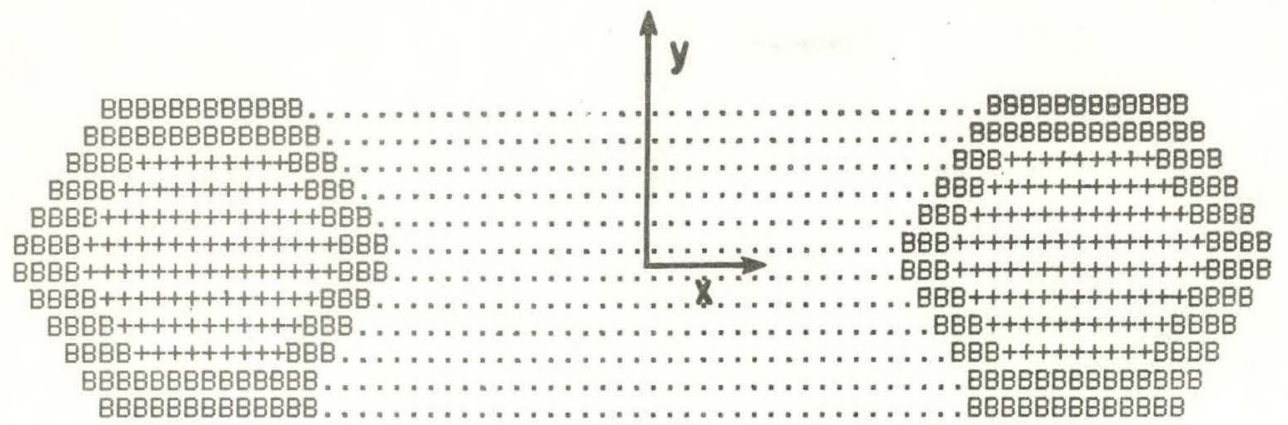

\section{$z=0$ Plane}

\section{Key $: B=$ Blanket \\ $+\approx$ Plasma and Vacuum $\cdot$ = Inside Void}

BBBBBBBBBBBBB8BBвB8BB8

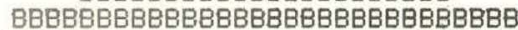
BBBBBBBBBB ++++++++++++++++++ BBBBBBBBBB

BBBBBBB ++++++++++++++++++++++++ BBBBBBB

BBBBBB $++++++++++++++++++++++++++++++\mathrm{BBBBBB}$

$\mathrm{BBBBB}+++++++++++++++++++++++++++++++++++++++\mathrm{BBBBB}$

$\mathrm{BBBBB}++++++++++++++++++++++++++++++++++++++++++++\mathrm{BBBBB}$

BBBBB ++++++++++++++++++++++++++++++++++++++++++++ BBBBB

$\mathrm{BBBBB}+++++++++++++++++++++++++++++++++++++++++++++\mathrm{BBBBB}$

$\mathrm{BBBB}+++++++++++++++++++++++++++++++++++++++++++++++++++++\mathrm{BBBB}$

$\mathrm{BBBB}++++++++++++++++++++++++++++++++++++++++++++++++++++++\mathrm{BBBB}$

$\mathrm{BBBB}+++++++++++++++++++++++++\mathrm{BBBBBB}+++++++++++++++++++++++++\mathrm{BBBB}$

$\mathrm{BBBB}+++++++++++++++++++\mathrm{BBBBBBBBBBBBBBBB}++++++++++++++++++++\mathrm{BBBB}$

$\mathrm{BBBB}+++++++++++++++++++\mathrm{BBBBBBBBBBBBBBBBBBBBBB}+++++++++++++++++++\mathrm{BBBB}$

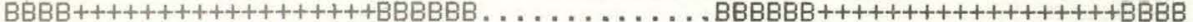

BBBB $+++++++++++++++++B B B B . \ldots \ldots \ldots \ldots \ldots . . .68 \mathrm{BBB}+++++++++++++++++B B B B$

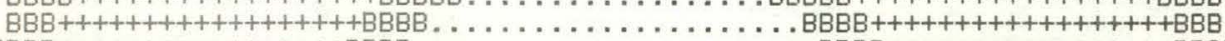

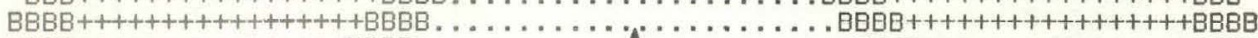

BBBB $++++++++++++++++B B B$ B. . . . . . . . . . . . . . . . . .

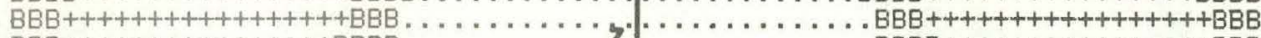

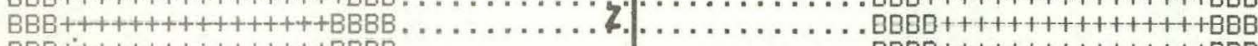

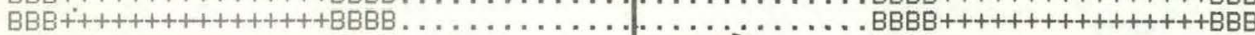

BBB $++++++++++++++++B B B B \ldots \ldots . \ldots \ldots$. . . . . . . . . . . . . .

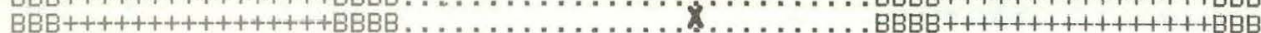

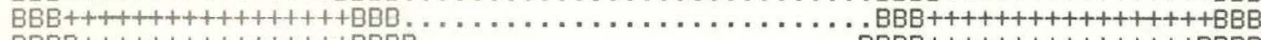

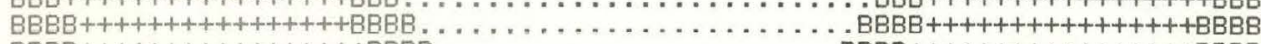

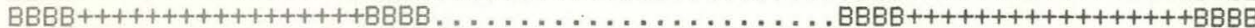

BBB $++++++++++++++++++B B B$ B. . . . . . . . . .

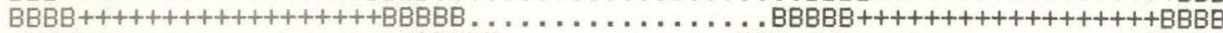

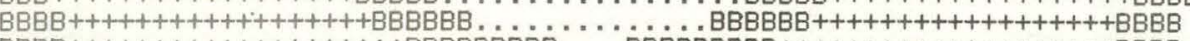

$\mathrm{BBBB}++++++++++++++++++++\mathrm{BBBBBBBBB} . . .8 \mathrm{BBBBBBBBB}+++++++++++++++++++\mathrm{BBBB}$

$\mathrm{BBBB}+++++++t++++++++++++\mathrm{BBBBBBBBBBBBBBBB}++++++++++++++++++++\mathrm{BBBB}$

$\mathrm{BBBB}++++++++++++++++++++++++\mathrm{BBBBBBBB}+++++++++++++++++++++++++\mathrm{BBBB}$

$\mathrm{BBBB}++++++++++++++++++++++++++++++++++++++++++++++++++++\mathrm{BBBB}$

$\mathrm{BBBB}++++++++++++++++++++++++++++++++++++++++++++++++++++++\mathrm{BBBB}$

$\mathrm{BBBBB}+++++++++++++++++++++++++++++++++++++++++++++++++\mathrm{BBBBB}$

$\mathrm{BBBBB}++++++++++++++++++++++++++++++++++++++++++++++++\mathrm{BBBBB}$

$\mathrm{BBBBB}+++++++++++++++++++++++++++++++++++++++++++\mathrm{BBBBB}$

BBBBBB $++++++++++++++++++++++++++++++++++++++\mathrm{BBBBBB}$

BBBBBBB $+++++++++++++++++++++++++++++++++\mathrm{BBBBBBB}$

$\mathrm{BBBBBBB}+++++++++++++++++++++++++++\mathrm{BBBBBBB}$

BBBBBBBBB ++++++++++++++++++ BBBBBBBBB

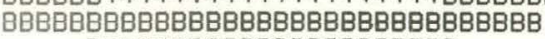

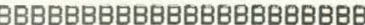

$$
y=0 \text { Plane }
$$

the torus geometry (for from the PICTURE program (ref.9) of blanket calculations. 